\title{
COMPARISON OF THE EFFICIENCY OF MESOPOROUS SILICAS AS ABSORBENTS FOR REMOVING NAPHTHALENE FROM CONTAMINATED WATER
}

\author{
ALI BALATI ${ }^{1}$, AFSANEH SHAHBAZI ${ }^{1, *}$, MOSTAFA M. AMINI ${ }^{2}$, \\ SEYED HOSSEIN HASHEMI ${ }^{1}$, and KHOSRO JADIDI ${ }^{2}$
}

\author{
${ }^{1}$ Environmental Sciences Research Institute, Shahid Beheshti University, G.C., Tehran 1983963113, Iran \\ 2 Department of Chemistry, Shahid Beheshti University, G.C., Tehran 1983963113, Iran \\ *Corresponding author: a_shahbazi@sbu.ac.ir
}

\begin{abstract}
Mesoporous silicas MCM-48 and SBA-15 were synthesized and characterized by X-ray diffraction (XRD), scanning electron microscopy (SEM), transmission electron microscopy (TEM) and Fourier transform infrared (FTIR) spectroscopy. Adsorption capacity of two mesoporous silica for removing naphthalene from waste water was determined. The results indicate that under similar conditions, SBA-15 had a better adsorption capacity than MCM-48. In this context, SBA-15 was modified using 3-aminopropyltrimethoxysilane and the effect of contact time, adsorbent dose, solution $\mathrm{pH}$ and concentration of naphthalene was investigated in batch adsorption systems. Solution $\mathrm{pH}$ appeared to be a key factor affecting the adsorption of naphthalene by $\mathrm{NH}_{2}-\mathrm{SBA}-15$. The adsorption experiments revealed that a higher percentage of up to $79.3 \%$ of naphthalene was adsorbed in highly acidic media ( $\mathrm{pH}$ of 2). The equilibrium data were analyzed using Langmuir and Freundlich isotherms and nonlinear regression analysis. This revealed that based on the correlation coefficient $\left(R^{2}=0.979\right)$ the Langmuir model provided the best fit to the results. The adsorption kinetic was determined using the pseudo-first order, pseudo-second order and Elovich kinetic models. Of the kinetics models tested, the pseudo-first-order equation provided the best fit to the results $\left(R^{2}=0.991\right)$ of the absorption of naphthalene by the adsorbent.
\end{abstract}

Keywords: mesoporous silica, naphthalene, adsorption, isotherm, kinetic

\section{Introduction}

Polycyclic aromatic hydrocarbon (PAHs) compounds are included on the priority pollutant lists of the European Union (EU) and United States Environmental Protection Agency (USEPA) because of their mutagenic, carcinogenic, and endocrine-disrupting properties (Vidal et al. 2011). They are ubiquitous environmental contaminants, which accumulate in coastal estuarine and marine sediments as well as aquatic organisms. Because it is difficult to degrade PAHs biologically they accumulate in the air, water bodies, soil and food. It is important, therefore, to develop an effective way of removing PAHs from the environment. The methods proposed include biodegradation (Ebihara and Bishop 2002), absorption (Chang et al. 2004) and high-energy electron beam irradiation (Cooper et al. 2002). However, most of these processes are difficult to handle and not always effective or economical. Of these methods, the addition of adsorbents to water/waste water is an efficient and economical way of removing PAHs from aqueous solutions (Vidal et al. 2011). Hence, it is important for managing environmental pollution to develop high capacity adsorbents for removing persistent organic pollutants from aqueous solutions (Lee et al. 2004). Mesostructured inorganic silicas such as M41S, HMS, MSU and SBA are good adsorbents because of their large surface area and pore volume, and uniform pore size (Sanz et al. 2012). MCM-48 with an interwoven and branched pore structure seems to be a good candidate for adsorbing PAHs from aqueous solutions (Lee et al. 2004). Of the Among mesoporous silicas, SBA-15 has one of the largest pore sizes, ranging between 4.6 and $30 \mathrm{~nm}$, with interconnected pore channels that make the ideal general purpose adsorbent (Sahbazi et al. 2012). There are very few studies on the adsorption of PAHs by SBA- 15 and MCM- 48 , especially the adsorption of various PAHs by functionalized SBA-15. It would, therefore, be of considerable interest to develop functionalized mesoporous silicas for adsorbing PAHs (Anbia and Amirmahmoodi 2011). Organic/inorganic hybrids, synthesized by chemically grafting amines onto mesoporous silicas, which have high adsorption energy or potential charge association, have been successfully used as adsorbents (Wang et al. 2006). The presence of free pairs of electrons on the amine group of amine-functionalized mesoporous silicas should increase their sorptive properties for organic compounds in aqueous solutions. $\mathrm{NH}_{2}$-SBA-15 is better at adsorbing halophenols than SBA-15 (Anbia and Amirmahmoodi 2011). Tao et al. (2010) report that adsorption of humic acid by SBA15 is substantially less than that adsorbed by aminopropyl-functionalized SBA-15. The adsorption capacity and rate of adsorption of $\mathrm{Cr}(\mathrm{IV})$ by aminopropyl-, imidazole- and triazole-functionalized SBA-15 are excellent (Li et al. 2008). Compared to many PAHs, naphthalene, the simplest $\mathrm{PAH}$, is a frequently recorded pollutant (Chang et al. 2004) and its efficient removal from waste water would greatly benefit the environment.

The aim of this study was to compare the adsorption of naphthalene from water by mesoporous MCM- 48 and 


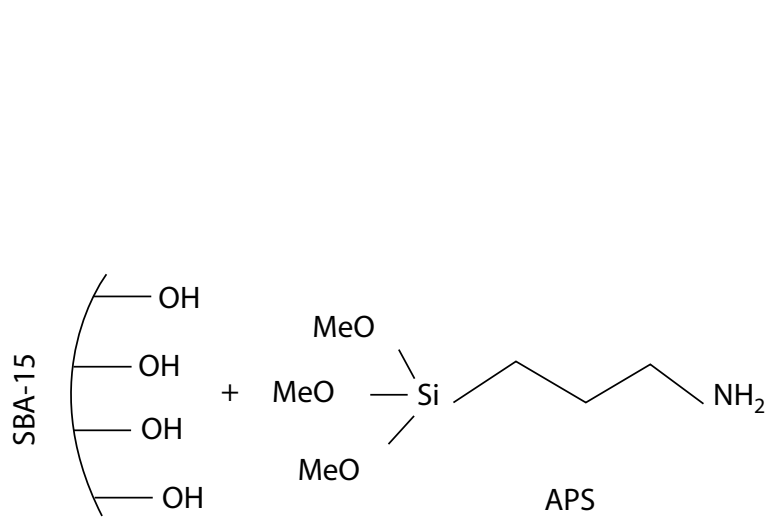

Fig. 1 Schematic illustration of the functionalization of SBA-15.

SBA-15, and find a more efficient mesoporous silica for removing this pollutant. In particular, this work reports the results of a study on the properties of amine-functionalized SBA-15 silica as naphthalene adsorbent. For this, the effects of various operating parameters such as adsorbent dose, $\mathrm{pH}$, and concentration of adsorbate and contact time were studied, and the adsorption features isothermally and kinetically modelled.

\section{Material and Methods}

\section{Chemicals and Reagents}

Tetraethyl orthosilicate (TEOS, 98\%), 3-aminopropyltrimethoxysilane (APS, 98\%), cetyltrimethylammonium bromide $\left(\mathrm{C}_{16} \mathrm{H}_{33}\left(\mathrm{CH}_{3}\right)_{3} \mathrm{NBr}\right.$; $\left.\mathrm{CTAB}\right)$, sodium hydroxide, dry toluene (99.9\%), methanol and naphthalene $\left(\mathrm{Mw}=128.17 \mathrm{~g} \mathrm{~mol}^{-1}\right.$, water solubility $=31.0 \mathrm{~g} \mathrm{l}^{-1}$ ) were purchased from Merck. Pluronic P123 $\left(\mathrm{Mw}=5800 \mathrm{~g} \mathrm{~mol}^{-1} ; \mathrm{EO}_{20}-\mathrm{PO}_{70} \mathrm{EO}_{20}\right)$ and $\mathrm{HCl}$ (37\%) from Aldrich. Aqueous solutions were prepared using double distilled water.

\section{Synthesis of MCM-48 Mesoporous Silica}

MCM-48 was synthesized using the conventional hydrothermal method as described by Schumacher et al. (1999). N-Hexadecyltrimethylammonium bromide was dissolved in deionized water, sodium hydroxide, and TEOS added to the mixture. The molar composition of the gel was $1.0 \mathrm{M}$ TEOS: $0.65 \mathrm{M}$ CTAB: $0.62 \mathrm{M} \mathrm{H}_{2} \mathrm{O}$. The solution was stirred for about $1 \mathrm{~h}$, transferred into a polypropylene reactor and then heated and kept at $110^{\circ} \mathrm{C}$ for 3 days. The product was filtered, washed with water and calcined at $550{ }^{\circ} \mathrm{C}$ for $6 \mathrm{~h}$.

\section{Synthesis and Modification of SBA-15 Mesoporous Silica}

The SBA-15 material was synthesized as previously reported (Zhao et al. 1998). In a typical synthesis, $4.0 \mathrm{~g}$ of P123 was dispersed in $120 \mathrm{~g}$ of water and $8.64 \mathrm{~g}$ of $2.0 \mathrm{M} \mathrm{HCl}$ solution at $40{ }^{\circ} \mathrm{C}$ was added while stirring, after which $8.54 \mathrm{~g}$ of tetraethyl orthosilicate was added to obtain a homogenous solution. The resultant gel mixture was continuously stirred at $40^{\circ} \mathrm{C}$ for $24 \mathrm{~h}$ and then placed in a Teflon-lined autoclave kept at $100{ }^{\circ} \mathrm{C}$ for 2 days. After cooling, the solid product was filtered off and template removed by calcination in air at $500^{\circ} \mathrm{C}$ for $4 \mathrm{~h}$. For modification, SBA-15 mesoporous silica ( $1.0 \mathrm{~g}$ ) was suspended in $30 \mathrm{ml}$ of dry toluene, then in an atmosphere of dry nitrogen $4 \mathrm{ml}$ of APS was added and the mixture refluxed for $10 \mathrm{~h}$. The solid product was recovered by filtration, washed with dichloromethane and ethanol and dried. It was then Soxhlet extracted with a mixture of ethanol and dichloromethane $(1: 1)$ in order to remove the residue of the silylating reagent. The material was dried at $70{ }^{\circ} \mathrm{C}$ under a vacuum overnight (Lombardo et al. 2012; Shahbazi et al. 2012). The way in which the SBA-15 was functionalized is schematically illustrated in Fig. 1.

\section{Characterization of Materials}

The X-ray diffraction (XRD) of samples were recorded on a Philips 1830 powder X-ray diffractometer using $\mathrm{Cu}-\mathrm{Ka}$ radiation over a range of $0.8^{\circ}$ to $6.6^{\circ}$, with a $2 \theta$ step size of $0.01^{\circ}$ and a step time of $1 \mathrm{~s}$. Fourier transform infrared (FTIR) spectra of materials were recorded within a 500 to $4000 \mathrm{~cm}^{-1}$ region on a BOMEM/MB Spectrometer in a $\mathrm{KBr}$ matrix. The morphology of the mesoporous materials was examined using a LEO 1455VP, Cambridge, U.K electron scanning microscope (SEM). TEM images were taken on a JEM-200CX instrument at an acceleration voltage of $200 \mathrm{kV}$. Single point BET analysis was carried out using a nitrogen adsorption technique and a Micromeritics ASAP 2010 analyzer.

\section{Batch Equilibrium Isotherm and Kinetic Experiments}

A series of naphthalene solutions (20\% v/v methanol) of different concentrations were prepared by diluting a stock solution of $500 \mathrm{mg} \mathrm{l}^{-1}$. The influence of experimental parameters, such as adsorbent dose (0.5-3.5 $\left.\mathrm{gl}^{-1}\right)$, $\mathrm{pH}$ of solution (2.0-10.0, step size: 1$)$, initial concentration (1-18 $\left.\mathrm{mg} \mathrm{l}^{-1}\right)$ and contact time (0.25-72 hours) were studied using batch processing. The $\mathrm{pH}$ of the naphthalene solution was adjusted by adding negligible volumes 
$(0-15 \mu \mathrm{l})$ of $0.1 \mathrm{M} \mathrm{HCl}$ or $0.1 \mathrm{M} \mathrm{NaOH}$. After reaching equilibrium the adsorbents were separated from the solution by centrifugation at $7000 \mathrm{rpm}$ for $10 \mathrm{~min}$. The concentration of naphthalene in the solution was measured using a UV-vis spectrophotometer (UV-Vis 2100 shimadzu) at $\lambda_{\max }=275.5 \mathrm{~nm}$. The adsorption capacity of the adsorbent and its efficiency in removing naphthalene was calculated using equation (1) and (2), respectively:

$q_{e}=\frac{\left(C_{0}-C_{e}\right) V}{W}$

$R=\frac{C_{0}-C_{t}}{C_{0}} \times 100$

where $q_{e}$ is the concentration of the adsorbed solute $\left(\mathrm{mg} \mathrm{g}^{-1}\right) ; C_{o}$ and $C_{e}$ are the initial and equilibrium concentrations of the solute in solution $\left(\mathrm{mg} \mathrm{l}^{-1}\right) ; V$ is the volume of the solution (l) and $W(\mathrm{~g})$ is the mass of the adsorbent.

Adsorption isotherm for determining the relationship between the amount of naphthalene adsorbed by $\mathrm{NH}_{2}$-SBA-15 and the concentration in the aqueous phase was recorded at $\mathrm{pH} 5$ using solutions of predetermined concentrations of naphthalene and a known amount of $\mathrm{NH}_{2}$-SBA-15 adsorbent. Adsorption data for naphthalene were fitted using the Langmuir and Freundlich isotherm equations. The Langmuir isotherm model assumes a surface with homogeneous binding sites, equivalent sorption energies and no interaction between the substances adsorbed (Lombardo et al. 2012). The mathematical equation defining this model is:

$q_{e}=\frac{q_{m} b C_{e}}{1+b C_{e}}$

The efficiency with which the naphthalene was adsorbed was checked using the dimensionless separation parameter $R_{L}$ in the following equation:

$R_{L}=\frac{1}{1+b C_{0}}$

where $q_{m}$ and $b$ represent the maximum adsorption capacity $\left(\mathrm{mg} \mathrm{g}^{-1}\right)$ and the energy constant $\left(1 \mathrm{mg}^{-1}\right)$ related to the heat of adsorption, respectively. $C_{o}$ and $C_{e}$ are the initial and equilibrium concentrations of the solute in solution $\left(\mathrm{mg} \mathrm{l}^{-1}\right)$. The value of $R_{L}$ indicates if the Langmuir isotherm is irreversible $\left(R_{L}=0\right)$, favourable $\left(0<R_{L}<1\right)$ or unfavourable $\left(R_{L}>1\right)$ (Huang et al. 2011a). Freundlich model takes the form of an exponential equation and therefore, assumes that the concentration of adsorbate on the adsorbent surface increases with increase in the concentration of adsorbate. This model predicts an infinite amount of adsorption (Qin et al. 2012), which is defined by the following equation:

$q_{e}=K_{f} C_{e}^{1 / n}$

where $K_{f}\left(\mathrm{mg}^{(\mathrm{n}-1) / \mathrm{n}} \mathrm{g}^{-1} \mathrm{l}^{-1}\right)$ and $n$ are Freundlich constants related to adsorption capacity and adsorption intensity, respectively.

The effect of contact time on naphthalene removal was determined by adding $0.6 \mathrm{~g}$ of adsorbent $\left(\mathrm{NH}_{2}-\mathrm{SBA}-15\right)$ to $200 \mathrm{ml}$ of a solution containing naphthalene at a concentration of $6 \mathrm{mg} \mathrm{l}^{-1}$ contained in $500 \mathrm{ml}$ glass Erlenmeyer flasks and stirred continuously at $25^{\circ} \mathrm{C}$ and $\mathrm{pH} 5$. The samples were collected at different time intervals.

In order to determine the sorption rate, the experimental data were analyzed using three kinetic models, namely, the pseudo-first-order (Eq. 6), pseudo-second-order (Eq. 7), and Elovich models (Eq. 8) (Benguella and Benaissa 2002):

$\log \left(q_{e}-q_{t}\right)=\log q_{e}-\frac{k_{1}}{2.303} t$

$\frac{t}{q_{t}}=\frac{1}{K_{2} q_{e}^{2}}+\frac{t}{q_{e}}$

$q_{t}=\frac{1}{\beta} \ln \alpha \beta+\frac{1}{\beta} \ln t$

where $q_{e}$ and $q_{t}$ are the amount of naphthalene adsorbed by the adsorbent in $\mathrm{mg} \mathrm{g}^{-1}$ at equilibrium and time $t$, respectively, $k_{1}$ is the constant of first-order adsorption in $\min ^{-1}$ and $k_{2}$ is the rate constant of second-order adsorption in $\mathrm{g} \mathrm{mg}^{-1} \mathrm{~min}^{-1}, \alpha$ is the initial adsorption rate in $\mathrm{mg} \mathrm{g}^{-1} \mathrm{~min}^{-1}$, and $\beta$ is related to the extent to which the surface is covered and the activation energy involved in chemisorption in $\mathrm{g} \mathrm{mg}^{-1}$.

\section{Results and Discussion}

\section{Adsorbent Characterization}

The XRD patterns of prepared samples are shown in

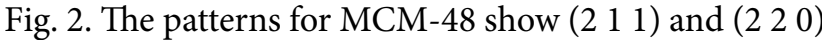
diffraction peaks, which indicate an Ia3d space group and that MCM-48 has a three-dimensional cubic mesoporous structure (Schumacher et al. 1999). The XRD patterns of SBA-15 and $\mathrm{NH}_{2}$-SBA-15 have a single strong peak ( $\left.\begin{array}{lll}1 & 0 & 0\end{array}\right)$ followed by two additional peaks ( $\begin{array}{lll}1 & 1 & 0 \text {, }\end{array}$ 200 ), which indicate they have a hexagonal lattice structure (Zhao et al. 1998). However, the sizes of the ( 110 , 200 ) peaks recorded for $\mathrm{NH}_{2}$-SBA-15 are significantly smaller due to the incorporation of organic groups inside the channels of SBA-15 (Shahbazi et al. 2011). This pattern confirms the presence of a 2D hexagonal structure to the pores and suggests that the modification process did 

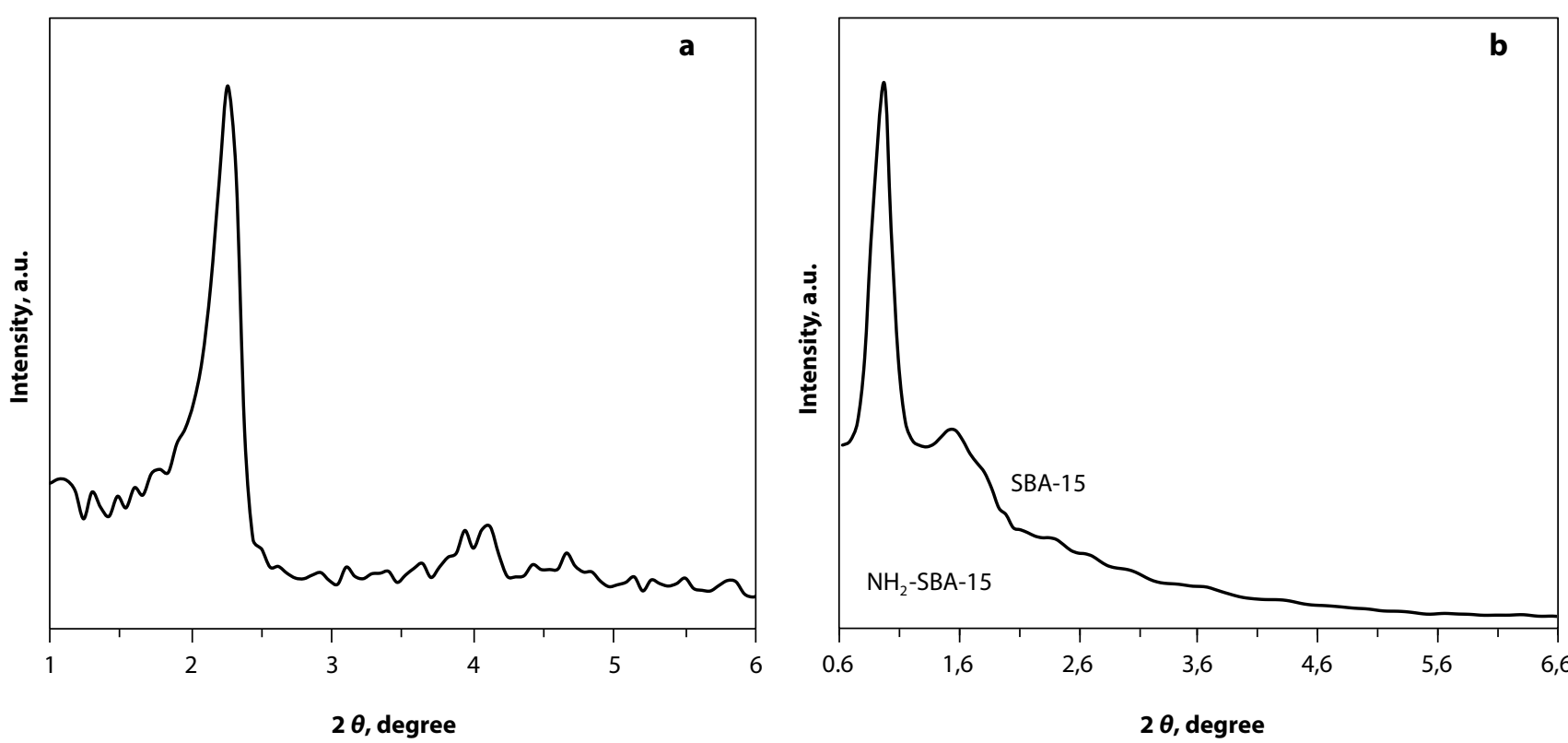

Fig. 2 The X-ray diffraction pattern of a) MCM-48; b) SBA-15 and $\mathrm{NH}_{2}-\mathrm{SBA}-15$.

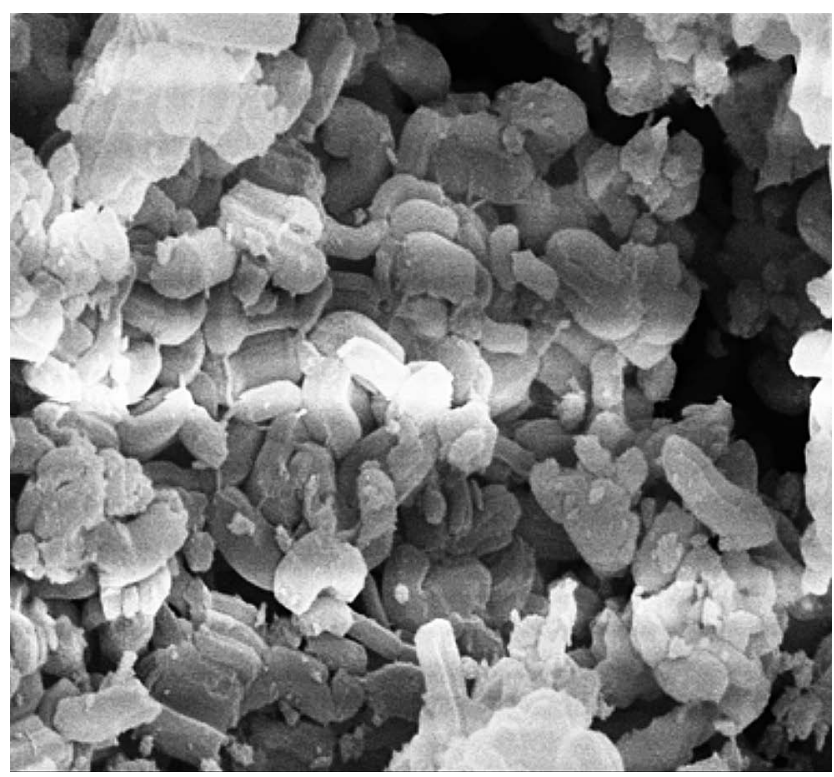

Fig. 3 SEM micrograph of SBA-15.

not affect the integrity of the framework of the ordered mesoporous SBA-15.

The SEM image of SBA-15 (Fig. 3) reveals that this mesoporous silica consists of well-defined wheat-like macro-structures aggregated in rope-like domains of a relatively uniform size. This result is in good agreement with the SBA-15 morphology presented in earlier reports (Shahbazi et al. 2012). Single point BET analysis indicated a surface area of $1238 \mathrm{~m}^{2} \mathrm{~g}^{-1}, 690 \mathrm{~m}^{2} \mathrm{~g}^{-1}$ and $560 \mathrm{~m}^{2} \mathrm{~g}^{-1}$ for MCM-48, SBA-15 and $\mathrm{NH}_{2}$-SBA-15, respectively.

TEM image of SBA-15 (Fig. 4) indicates well-ordered hexagonal arrays of mesopores (1D channels) and further confirms that SBA-15 has a 2D p6mm hexagonal struc-

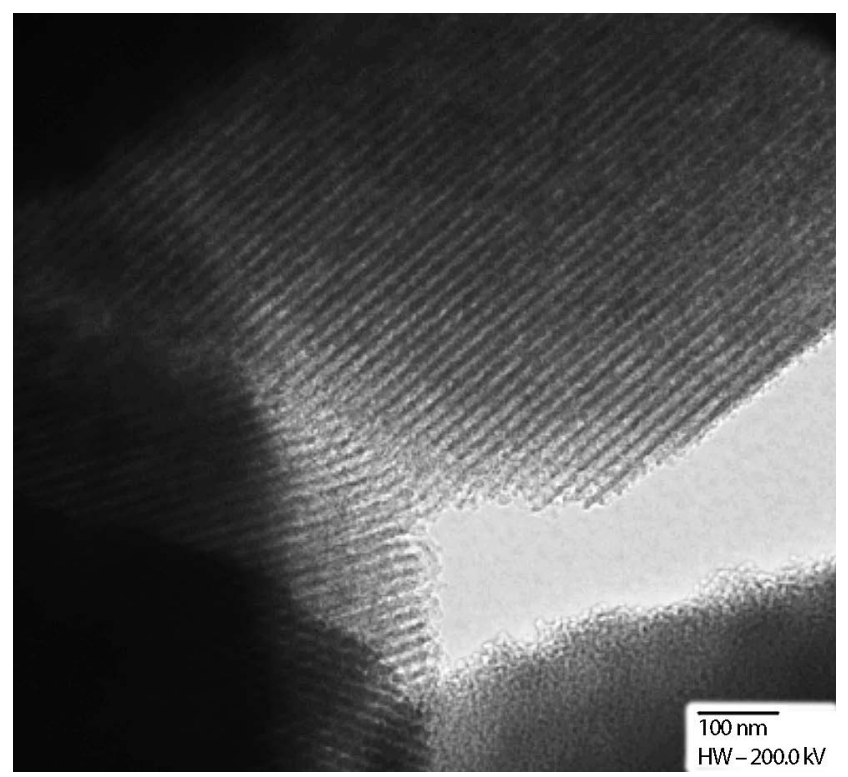

Fig. 4 TEM micrograph of SBA-15.

ture. Channel direction of the 2D-hexagonal structures was parallel to the thickness direction of the nanostructured hexagonal platelet morphologies (Zhao et al. 1998).

The IR spectrum of MCM-48 is shown in Fig. 5a. The peaks at $1078 \mathrm{~cm}^{-1}$ and $797 \mathrm{~cm}^{-1}$ are associated with Si-O-Si vibrations (Schumacher et al. 1999). Figure 5b shows the IR spectrum of SBA- 15 before and after modification. As can be seen, there are several new bands in the amino-functionalized SBA-15. Peaks at 2859 and 2937 are due to $\mathrm{C}-\mathrm{H}$ stretching vibration and that at $1579 \mathrm{~cm}^{-1}$ to $\mathrm{N}-\mathrm{H}$ (primary amine) bending vibration of the amine group on the surface of the silica (Anbia et al. 2011). 

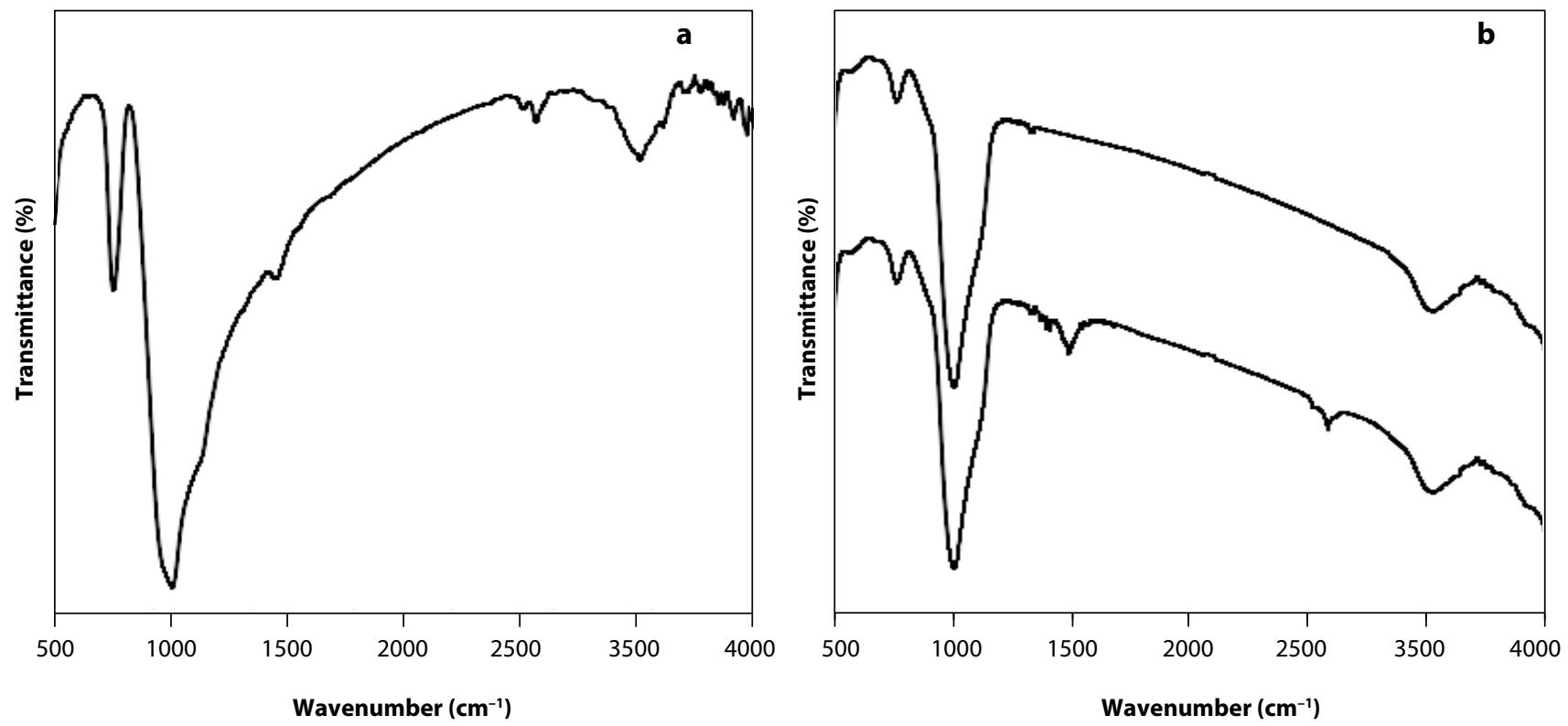

Fig. 5 The FT-IR spectra of a) MCM-48; b) SBA-15 and $\mathrm{NH}_{2}-\mathrm{SBA}-15$.

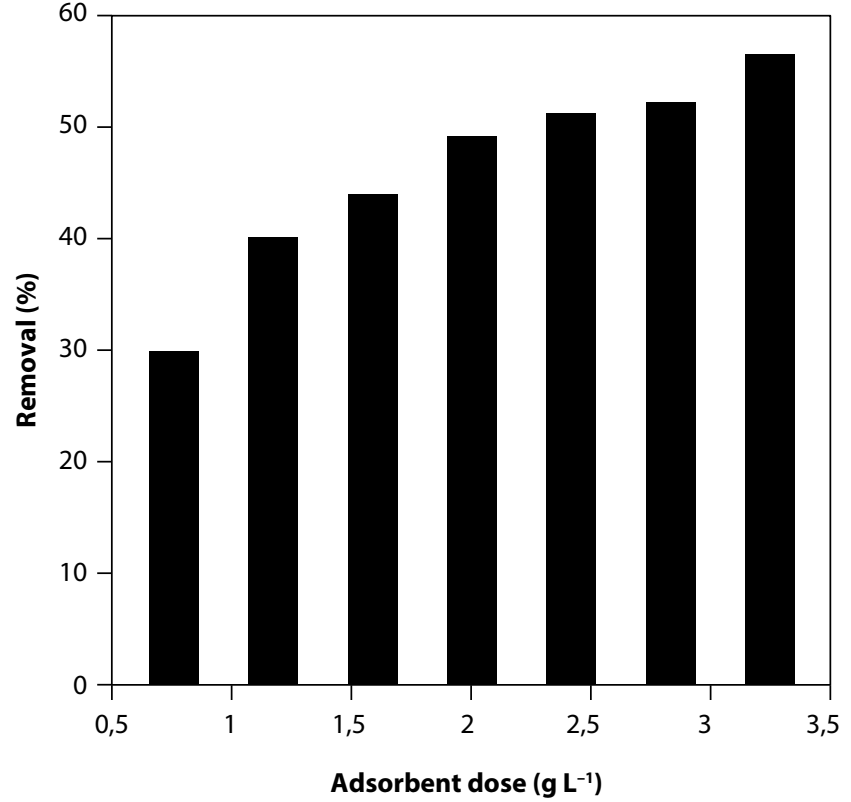

Fig. 6 Effect of the dose of the adsorbent on the percentage of naphthalene removed by $\mathrm{NH}_{2}-\mathrm{SBA}-15$. (Conditions: $20 \mathrm{ml}$ of $7 \mathrm{mg} \mathrm{I}^{-1}$ of naphthalene solution, agitation time $24 \mathrm{~h}$, temperature of $25^{\circ} \mathrm{C}$ ).

\section{Effect of the Tpe of Adsorbent on Naphthalene Removal}

The adsorption efficiencies of MCM-48 and SBA-15 were compared under the same sorption conditions. According to the results, the capacity for adsorbing naphthalene was 1.76 times higher for SBA-15 than MCM-48 ( $0.67 \mathrm{mg} \mathrm{g}^{-1}$ vs. $0.38 \mathrm{mg} \mathrm{g}^{-1}$ ). This could be due both the micro- and mesoporosity structure and larger pore diameter of SBA-15, which improve the diffusion and mass transfer rates of adsorption processes (Huang et al. 2011b). Therefore, SBA-15 was selected for functionaliza- tion using APS and the follow up experiments on its use as an adsorbent.

\section{Effect of the Adsorbent Dosage}

Experiments were done to establish an appropriate adsorbent dose for naphthalene removal from aqueous solutions (Fig. 6). The percentage of naphthalene removed increased from 29.9 to 53.6 with increase in the dosage of $\mathrm{NH}_{2}$-SBA-15 from 0.5 to $3.5 \mathrm{~g} \mathrm{l}^{-1}$ due to the increase in contact surface of adsorbent and greater availability of the adsorbent (Shahbazi et al. 2012). Because of the negligible increase in percentage removal with increase in adsorbent dosage between 3 to $3.5 \mathrm{~g} \mathrm{l}^{-1}$ a dose of $3 \mathrm{~g} \mathrm{l}^{-1}$ of $\mathrm{NH}_{2}-\mathrm{SBA}-15(R=52.2 \%)$ was chosen as the optimum adsorbent dosage for use in further experiments.

\section{Effect of $\mathrm{pH}$}

The efficiency with which naphthalene is removed by $\mathrm{NH}_{2}-\mathrm{SBA}-15$ at various $\mathrm{pHs}$ is presented in Fig. 7. The $\mathrm{pH}$ of solution may affect the surface charge of the adsorbent by the protonation of the functional groups, free surface hydroxyl groups and the degree of ionization and hydrolysis of the species present in solution (Dimos et al. 2009). The highest percentage adsorption of naphthalene by $\mathrm{NH}_{2}-\mathrm{SBA}-15$ was recorded at $\mathrm{pH}=2.0$ (79.3\%). With increase in $\mathrm{pH}$ from 2 to 8 the percentage adsorption of naphthalene decreased from $79.3 \%$ to $50.8 \%$. However, the percentage of naphthalene removed increased from $58.1 \%$ to $62.3 \%$ with increase in $\mathrm{pH}$ from 9.0 to 10.0 . It is highly likely that interactions occurred between the positively charged amine functional groups of the $\mathrm{NH}_{2}$-SBA-15 adsorbent in acidic media (Li et al. 2013) and the delocalized electron system of the aromatic ring of naphthalene (Horak et al. 2004). 


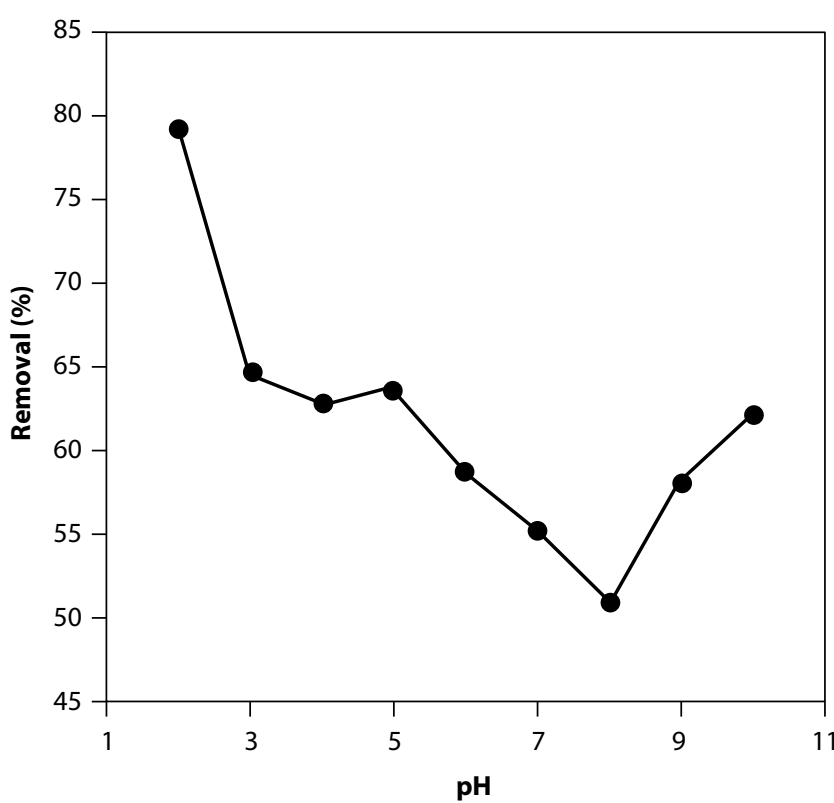

Fig. 7 Effect of $\mathrm{pH}$ of the solution on the percentage of naphthalene removed by $\mathrm{NH}_{2}$-SBA-15. (Conditions: $0.06 \mathrm{~g}$ of adsorbent, $20 \mathrm{ml}$ of $7 \mathrm{mg} \mathrm{l}^{-1}$ of naphthalene solution, agitation time $24 \mathrm{~h}$ and temperature $25^{\circ} \mathrm{C}$ ).

\section{Adsorption Isotherms}

In order to show the sorption behaviour and estimate the adsorption capacity, adsorption isotherms were studied. The fits of the nonlinear Langmuir and Freundlich adsorption isotherms to the experimental results for the absorption of naphthalene are shown in Fig. 8. The $b$, $q_{m}, n, K_{f}$ values and the nonlinear regression correlation coefficients $\left(R^{2}\right)$ for Langmuir and Freundlich isotherms are given in Table 1. Both isotherms indicate a sharp initial slope indicating that the adsorbent operates at high efficiency at a low concentration and becomes saturated at high adsorbate concentrations. The constant of the adsorption capacity of the adsorbent i.e. $K_{f}$ in the Freundlich isotherm is $0.922\left(\mathrm{mg}^{(\mathrm{n}-1) / \mathrm{n}} \mathrm{g}^{-1} \mathrm{l}^{-1}\right)$. The other Freundlich constant, $n$, is a measure of both the relative magnitude and diversity of energies associated with the adsorption of naphthalene onto $\mathrm{NH}_{2}-\mathrm{SBA}-15$ and that the numerical values of $1 / n$ are $<$ unity, indicate that the naphthalene was efficiently adsorbed by $\mathrm{NH}_{2}-\mathrm{SBA}-15$.

The high values of correlation coefficients indicate that the data conform well to the Langmuir model. The value of $q_{m}=1.92 \mathrm{mg} \mathrm{g}^{-1}$ predicted from the Langmuir curve for naphthalene is similar to the $1.72 \mathrm{mg} \mathrm{g}^{-1}$ recorded.

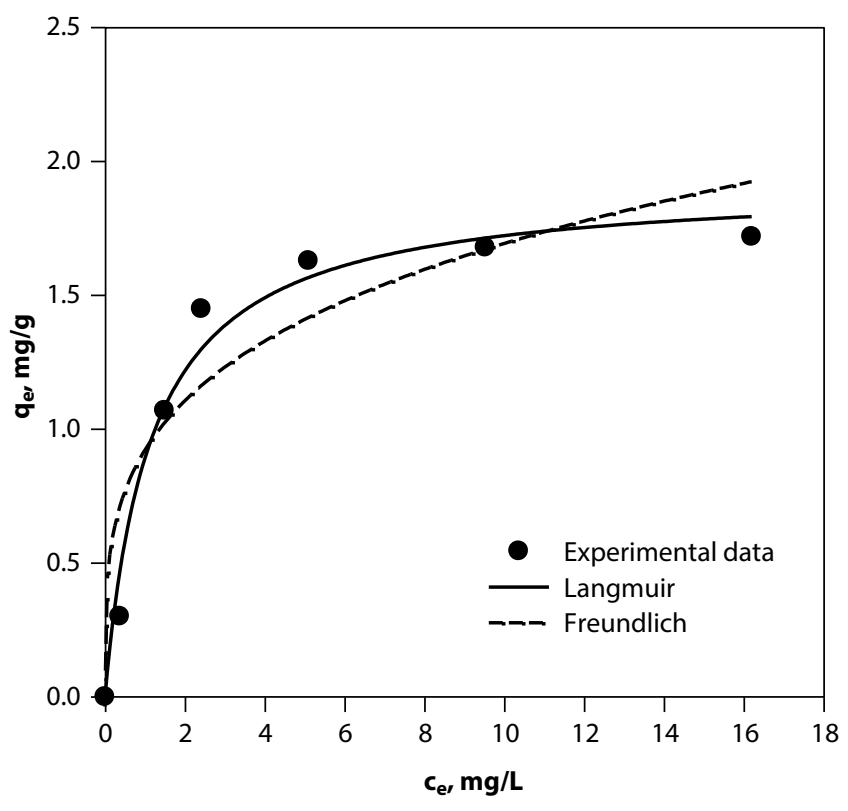

Fig. 8 Isotherms for the adsorption of naphthalene by $\mathrm{NH}_{2}-\mathrm{SBA}-15$. (Conditions: $0.06 \mathrm{~g}$ of adsorbent, agitation time $24 \mathrm{~h}, \mathrm{pH} 5$, temperature $25^{\circ} \mathrm{C}$ and $20 \mathrm{ml}$ of different concentrations of naphthalene solution).

Similar results are reported for the adsorption of PAHs by different adsorbents (Anbia and Moradi 2009). Therefore, the adsorption process is likely to consist of the formation of a monolayer cover of naphthalene on the surface of the adsorbent. The efficiency of the $\mathrm{NH}_{2}$-SBA-15 adsorbent in adsorbing naphthalene can be defined in terms of the separation factor $\left(R_{L}\right)$, the values of which are presented in Table 2. As the values are $0<R_{L}<1$ the efficiency of adsorption of naphthalene of this adsorbent is high.

\section{Adsorption Kinetics}

An understanding of adsorption kinetics is a basic requirement for designing adsorption systems. Equilibrium kinetic data for a specific adsorbate/adsorbent system can be obtained from an experimental study of the adsorption of a system after different periods of time (Gök et al. 2008). The amount of naphthalene adsorbed by $\mathrm{NH}_{2}$-SBA-15 was determined as a function of the exposure time. Figure 9 shows the time dependence of the amount of molecule solute adsorbed using this adsorbent.

The parameters of the kinetic models and the regression correlation coefficients $\left(R^{2}\right)$ are listed in Table 2 .

Table 1. Isotherm parameters for adsorption of naphthalene onto $\mathrm{NH}_{2}-\mathrm{SBA}-15$

\begin{tabular}{|c|c|c|c|c|c|c|c|}
\hline \multirow[b]{3}{*}{$\begin{array}{c}q_{m, \exp } \\
\left(\mathrm{mg} \mathrm{g}^{-1}\right)\end{array}$} & \multicolumn{7}{|c|}{ Isotherm models } \\
\hline & \multicolumn{4}{|c|}{ Langmuir } & \multicolumn{3}{|c|}{ Freundlich } \\
\hline & $\begin{array}{r}q_{m, c a l} \\
\left(\mathrm{mg} \mathrm{g}^{-1}\right)\end{array}$ & $\begin{array}{c}b \\
\left(1 \mathrm{mg}^{-1}\right) \\
\end{array}$ & $R_{L}$ & $R^{2}$ & $\begin{array}{c}K_{f} \\
\left(\mathrm{mg}^{(\mathrm{n}-1) / \mathrm{n}} \mathrm{g}^{-1} \mathrm{I}^{1}\right) \\
\end{array}$ & $n$ & $R^{2}$ \\
\hline 1.72 & 1.92 & 0.864 & 0.060 & 0.979 & 0.922 & 3.77 & 0.880 \\
\hline
\end{tabular}


Table 2 Kinetic Parameters for adsorption of naphthalene onto $\mathrm{NH}_{2}$-SBA-15

\begin{tabular}{|l|c|c|}
\hline Kinetic model & Parameter & Value \\
\hline \multirow{4}{*}{ Pseudo-first-order } & $q_{e}\left(\mathrm{mg} \mathrm{g}^{-1}\right)$ & 1.71 \\
\cline { 2 - 3 } & $k_{1}\left(\mathrm{~min}^{-1}\right)$ & 0.678 \\
\hline \multirow{4}{*}{ Pseudo-second-order } & $R^{2}$ & 0.991 \\
\hline \multirow{3}{*}{ Elovich } & $q_{e}\left(\mathrm{mg} \mathrm{g}^{-1}\right)$ & 1.92 \\
\cline { 2 - 3 } & $k_{2}\left(\mathrm{~g} \mathrm{mg}^{-1} \mathrm{~min}^{-1}\right)$ & 0.449 \\
\cline { 2 - 3 } & $R^{2}$ & 0.959 \\
\cline { 2 - 3 } & $\alpha\left(\mathrm{mg} \mathrm{g}^{-1} \mathrm{~min}^{-1}\right)$ & 6.22 \\
\cline { 2 - 3 } & $\beta\left(\mathrm{g} \mathrm{mg}^{-1}\right)$ & 0.001 \\
\hline
\end{tabular}

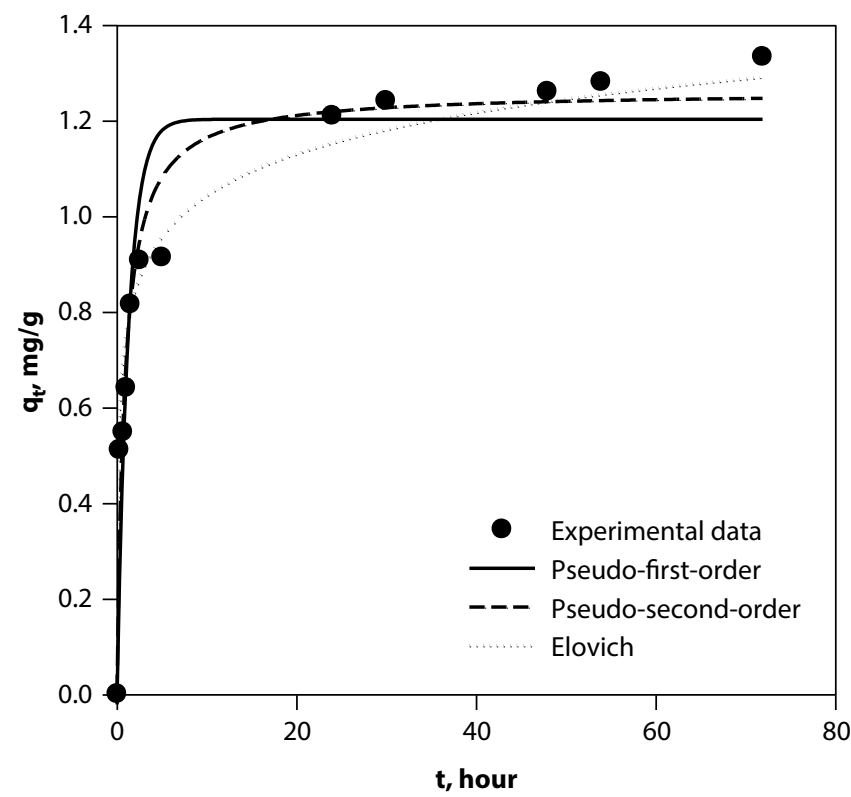

Fig. 9 Kinetics of the adsorption of naphthalene by $\mathrm{NH}_{2}-\mathrm{SBA}-15$. (Conditions: $0.3 \mathrm{~g}$ of adsorbent, $100 \mathrm{ml}$ of $6 \mathrm{mg} \mathrm{l}^{-1}$ of naphthalene, agitation time $24 \mathrm{~h}, \mathrm{pH} 5$, temperature $25^{\circ} \mathrm{C}$ ).

The removal efficiency increased sharply during the first 5 hours and then remains constant after 24 hours. Similar results are reported by Vidal et al. (2011) for the adsorption of PAHs onto periodic mesoporous organosilica (PMO). After $72 \mathrm{~h}$ the maximum percentage removed was about $72 \%$. The Elovich model assumes that the rate of adsorption changes over time depending upon the percentage of the surface of the adsorbent covered. This kinetic model is valid for systems in which the adsorbing surface is heterogeneous (Pérez-Marín et al. 2007). The Elovich rate equation is commonly used to describe the sorption behaviour in which the equilibrium rate is rapidly reached and slowly decreases in the later periods of the sorption process (Chang et al. 2004). The value of Elovich $\alpha$ constant recorded is 6.22 . This indicates the rate of sorption and the 0.001 for $\beta$ the surface coverage.
Elovich constants reveal that the rate of adsorption of naphthalene was rapid in the initial stages and the surface available for adsorption of the sorbate decreased with time. Comparing the values of $R^{2}$ for the pseudo-first-order, pseudo-second-order and Elovich equations indicate that the pseudo-first-order was better than the two others and could be used to predict the adsorption kinetics of naphthalene by the $\mathrm{NH}_{2}$-SBA- 15 adsorbent. Furthermore, the results indicate that the experimentally determined adsorption capacity $\left(1.33 \mathrm{mg} \mathrm{g}^{-1}\right)$ is similar to that predicted $\left(1.71 \mathrm{mg} \mathrm{g}^{-1}\right)$ by the pseudo-first order model.

\section{Conclusions}

In this study, the efficiencies of two mesoporous silicas, MCM-48 and SBA-15, in removing naphthalene from waste water were compared. After determining that SBA-15 was better at removing naphthalene, this mesoporous silica was functionalized with amine groups. The optimum conditions for the removal of naphthalene using $\mathrm{NH}_{2}$-SBA-15 adsorbent is a $\mathrm{pH}$ of 5.0 and dose of $3 \mathrm{~g} \mathrm{l}^{-1}$, which resulted in a removal efficiency of $79.3 \%$. Of the equilibrium isotherm models investigated, the Langmuir model provided a good fit to the experimental data with high $R^{2}(0.979)$ and $q_{m}\left(1.92 \mathrm{mg} \mathrm{g}^{-1}\right)$ values. The kinetic experiments showed that the adsorption of naphthalene by the $\mathrm{NH}_{2}$-SBA-15 adsorbent was rapid and maximum adsorption capacities were achieved in approximately $24 \mathrm{~h}$. The results of the kinetic studies indicate that the best fitting kinetic model was the pseudo-first order $\left(R^{2}=0.991\right)$, followed by the Elovich $\left(R^{2}=0.979\right)$ and the pseudo-second order equations $\left(R^{2}=0.959\right)$.

\section{Acknowledgements}

The authors gratefully acknowledge the Iranian Nano Technology Initiative Council and Shahid Beheshti University for funding this research.

\section{REFERENCES}

Anbia M, Amirmahmoodi S (2011) Adsorption of phenolic compounds from aqueous solutions using functionalized SBA-15 as a nano-sorbent. Scientia Iranica 18: 446-452.

Anbia M, Moradi SE (2009) Adsorption of naphthalene-derived compounds from water by chemically oxidized nanoporous carbon. Chem Eng J 148: 452-458.

Benguella B, Benaissa H (2002) Cadmium removal from aqueous solutions by chitin: kinetic and equilibrium studies. Water Res 36: 2463-2474.

Chang CF, Chang CY, Chen KH, Tsai WT, Shie JL, Chen YH (2004) Adsorption of naphthalene on zeolite from aqueous solution. J Colloid Interface Sci 277: 29-34.

Cooper WJ, Nickelsen MG, Green RV, Mezyk SP (2002) The removal of naphthalene from aqueous solutions using high-energy electron beam irradiation. Radiat Phys Chem 65: 571-577. 
Dimos K, Stathi P, Karakassides MA, Deligiannakis Y (2009) Synthesis and characterization of hybrid MCM-41 materials for heavy metal adsorption. Micropor Mesopor Mat 126: 65-71.

Ebihara T, Bishop P (2002) Influence of supplemental scetate on bioremediation for dissolved polycyclic aromatic hydrocarbons. J Environ Eng 128: 505-513.

Gök Ö, Özcan AS, Özcan A (2008) Adsorption kinetics of naphthalene onto organo-sepiolite from aqueous solutions. Desalination 220: 96-107.

Horak J, Maier NM, Lindner W (2004) Investigations on the chromatographic behavior of hybrid reversed-phase materials containing electron donor-acceptor systems: II. Contribution of $\pi-\pi$ aromatic interactions. J Chromatogr A 1045: 43-58.

Huang CH, Chang KP, Ou HD, Chiang YC, Wang CF (2011a) Adsorption of cationic dyes onto mesoporous silia. Micropor Mesopor Mat 141: 102-109.

Huang CH, Chang KP, Ou HD, Chiang YC, Chang EE, Wang CF (2011b) Characterization and application of Ti-containing mesoporous silica for dye removal with synergistic effect of coupled adsorption and photocatalytic oxidation. J Hazard Mater 186: 1174-1182.

Lee JW, Shim WG, Moon H (2004) Adsorption equilibrium and kinetics for capillary condensation of trichloroethylene on MCM-41 and MCM-48. Micropor Mesopor Mat 73: 109-119.

Li L, Fan L, Sun M, Qiu H, Li X, Duan H, Luo C (2013) Adsorbent for chromium removal based on graphene oxide functionalized with magnetic cyclodextrin-chitosan. Colloid Surface B 107: 76-83.

Li J, Wang L, Qi T, Zhou Y, Liu C, Chu J, Zhang Y (2008) Different $\mathrm{N}$-containing functional groups modified mesoporous adsorbents for $\mathrm{Cr}(\mathrm{VI})$ sequestration: Synthesis, characterization and comparison. Micropor Mesopor Mat 110: 442-450.

Lombardo M. V, Videla M, Calvo A, Requejo FG, Soler-Illia GJAA (2012) Aminopropyl-modified mesoporous silica SBA-15 as recovery agents of $\mathrm{Cu}(\mathrm{II})$-sulfate solutions: Adsorption efficiency, functional stability and reusability aspects. J Hazard Mater 223: $53-62$.
Pérez-Marín AB, Zapata VM, Ortuño JF, Aguilar M, Sáez J, Lloréns M (2007) Removal of cadmium from aqueous solutions by adsorption onto orange waste. J Hazard Mater 139: 122-131.

Qin Q, Liu K, Fu D, Gao H (2012) Effect of chlorine content of chlorophenols on their adsorption by mesoporous SBA-15. J Environ Sci 24: 1411-1417.

Sanz R, Calleja G, Arencibia A, Sanz-Pérez ES (2012) Amino functionalized mesostructured SBA-15 silica for $\mathrm{CO}_{2}$ capture: Exploring the relation between the adsorption capacity and the distribution of amino groups by TEM. Micropor Mesopor Mat 158: 309-317.

Schumacher K, Grünun M, Unger KK (1999) Novel synthesis of spherical MCM-48. Micropor Mesopor Mat 27: 201-206.

Shahbazi A, Younesi H, Badiei A (2011) Functionalized SBA-15 mesoporous silica by melamine-based dendrimer amines for adsorptive characteristics of $\mathrm{Pb}(\mathrm{II}), \mathrm{Cu}(\mathrm{II})$ and $\mathrm{Cd}(\mathrm{II})$ heavy metal ions in batch and fixed bed column. Chem Eng J 168: 505-518.

Shahbazi A, Younesi H, Badiei A (2012) Batch and fixed-bed column adsorption of $\mathrm{Cu}(\mathrm{II}), \mathrm{Pb}(\mathrm{II})$ and $\mathrm{Cd}(\mathrm{II})$ from aqueous solution onto functionalised SBA-15 mesoporous silica. Can J Chem Eng 91: 739-750.

Tao Q, Xu Z, Wang J, Liu F, Wan H, Zheng S (2010) Adsorption of humic acid to aminopropyl functionalized SBA-15. Micropor Mesopor Mat 131: 177-185.

Vidal CB, Barros AL, Moura CP et al. (2011) Adsorption of polycyclic aromatic hydrocarbons from aqueous solutions by modified periodic mesoporous organosilica. J Colloid Interface Sci 357: 466-473.

Wang X, Chan JCC, Tseng YH, Cheng S (2006) Synthesis, characterization and catalytic activity of ordered SBA-15 materials containing high loading of diamine functional groups. Micropor Mesopor Mat 95: 57-65.

Zhao D, Feng J, Huo Q et al (1998) Triblock copolymer syntheses of mesoporous silica with periodic 50 to 300 angstrom pores. Science 279: 548-552. 